\title{
Educação popular, democracia e Estado: os desafios da educação em direitos humanos
}

- Educación popular, democracia y Estado: los retos de la educación en derechos humanos

- Popular education, democracy, and the state: the challenges of human rights education

Francisca Rodrigues de Oliveira Pini'

Resumo: Este artigo tem como objetivo refletir sobre Educação popular, democracia, Estado e os desafios da educação em direitos humanos. Problematizará a relação do Estado, democracia e educação em direitos humanos, no contexto da fragilidade das instituições democráticas no Brasil. Abordará a educação popular de Paulo Freire, como práxis da educação em direitos humanos, na disputa com a concepção da educação bancária, mercantil, domesticadora das classes subalternas e, por fim, apresentam os desafios da democracia e educação em direitos humanos na contraditória sociedade capitalista, e a exigência das lutas sociais para novos enfrentamentos, que contribuam com a educação em direitos humanos como projeto de educação emancipadora, para que possamos construir novos enfrentamentos, por meio das lutas sociais, e contribuir para que este projeto de Educação permeie as múltiplas dimensões que envolvem as relações sociais: educação, a mídia, o sistema de justiça e segurança pública e a sociedade em geral.

1 Doutorado em Serviço Social pela PUC de São Paulo (2006). É docente do Curso de Serviço Social e do Programa de Pós-Graduação em Serviço Social e Políticas Públicas da Unifesp. Integrante do Grupo de Estudo, Pesquisa e Extensão sobre Crianças, Adolescentes e Famílias (GCAF/Unifesp) e do Conselho Editorial da Revista Uni Freire/ IPF. pinifrancisca@gmail.com 
Palavras-chave: Educação popular. Democracia. Estado. Educação em direitos humanos.

Resumen: Este artículo pretende reflexionar sobre la educación popular, la democracia, el Estado y los retos de la educación en derechos humanos. Se discutirá la relación entre el Estado, la democracia y la educación en derechos humanos, en el contexto de la fragilidad de las instituciones democráticas en Brasil. Abordará la educación popular de Paulo Freire, como una praxis de la educación en derechos humanos, en la disputa con la concepción de la educación bancaria, mercantil, domesticadora de las clases subalternas y, finalmente, presentará los desafíos de la democracia y la educación en derechos humanos en la contradictoria sociedad capitalista, y la demanda de las luchas sociales por nuevas confrontaciones, que contribuyan a la educación en derechos humanos como proyecto educativo emancipador, para que podamos construir nuevas confrontaciones, a través de las luchas sociales, y contribuir para que este proyecto de Educación permee las múltiples dimensiones que involucran las relaciones sociales: la educación, los medios de comunicación, el sistema de justicia y seguridad pública y la sociedad en general.

Palabras clave: Educación popular. La democracia. Estado. Educación en derechos humanos.

\begin{abstract}
This article aims to reflect on popular education, democracy, the State and the challenges of human rights education. It will problematize the relationship between the State, democracy and human rights education, in the context of the fragility of democratic institutions in Brazil. It will approach Paulo Freire's popular education, as a praxis of education in human rights, in the dispute with the conception of banking education, mercantile, domesticating the subordinate classes and, finally, it will present the challenges of democracy and education in human rights in the contradictory capitalist society, and the requirement of social struggles for new confrontations, which contribute to the education in human rights as an emancipating education project, so that we can build new confrontations, through social struggles, and contribute so that this Education project permeates the multiple dimensions that involve social relations: education, the media, the justice and public security system, and society in general.
\end{abstract}

Keywords: Popular education. Democracy. State. Education in human rights. 


\section{Vozes Mulheres}

A voz de minha bisavó ecoou criança nos porões do navio. ecoou lamentos de uma infância perdida.

A voz de minha avó ecoou obediência aos brancos-donos de tudo.

A voz de minha mãe ecoou baixinho revolta no fundo das cozinhas alheias debaixo das trouxas roupagens sujas dos brancos pelo caminho empoeirado rumo à favela.

A minha voz ainda ecoa versos perplexos com rimas de sangue

fome.

A voz de minha filha recolhe todas as nossas vozes recolhe em si as vozes mudas caladas engasgadas nas gargantas.

A voz de minha filha recolhe em si a fala e o ato.

O ontem - o hoje - o agora. Na voz de minha filha se fará ouvir a ressonância o eco da vida-liberdade.

Conceição Evaristo Poemas da recordação e outros movimentos 


\title{
Introdução
}

Este artigo é fruto das reflexões realizadas no painel "Desafios e perspectivas da Educação em Direitos Humanos no Brasil"2, ocorrido no Encontro Nacional de Educação em Direitos Humanos, da Rede Brasileira de Educação em Direitos Humanos (ReBEDH), em 2 e 3 de dezembro de 2020.

O painel expressou o engajamento e a trajetória de muitas mulheres e homens que lutam no Brasil e na América Latina por uma educação libertadora e promotora da Educação em Direitos Humanos. A poesia da escritora Conceição Evaristo, "Vozes Mulheres", ecoou durante a exposição como forma de prestar uma femenagem ${ }^{3}$ às mulheres que dialogavam naquele painel, mas, sobretudo, às muitas mulheres que acompanhavam a exposição naquele momento e ainda para dar visibilidade à literatura afro-brasileira e africana, tão ausentes nos sistemas de ensino, tanto na educação básica como no ensino superior. Foi também uma forma de assegurar a memória, a verdade e a justiça da nossa formação sócio-histórica, já que a urgência dos estudos da história afro-brasileira, africana e indígena, em todos os cantos do Brasil, é exigência e compromisso ético dos que atuam na promoção da educação em direitos humanos.

O currículo escolar é um dos espaços para a disputa de projetos educacionais, para que se possa ter a experiência tensa da democracia, propondo e criando soluções coletivas para os problemas cotidianos, orientando e fomentando as condições reais para a participação de estudantes, trabalhadoras(es) e familiares em conselhos de escola, grêmios e comitês (FREIRE, 2003).

Assim, é possível afirmar que há uma estrutura social que impede os avanços de outras epistemologias na construção do conhecimento e que podemos nominá-la de racismo estrutural. Para Almeida (2018),

\begin{abstract}
o racismo transcende o âmbito da ação individual, e, segundo, ao frisar a dimensão do poder como elemento constitutivo das relações raciais, não somente o poder de um indivíduo de uma raça sobre outro, mas de um grupo sobre outro, algo possível quando há o controle direto ou indireto de determinados grupos sobre o aparato institucional (p. 36).
\end{abstract}

Por isso, um dos maiores desafios da atuação educativa é intensificar os conhecimentos sobre educação popular em direitos humanos, para que se consolide como uma práxis teórico-político-cultural e pedagógica e contri-

2 Participantes do painel: Francisca Rodrigues Pini, (IPF / Unifesp), Maria de Nazaré Tavares Zenaide (UFPB), Nair Bicalho (UnB) e a mediadora Néri de Barros Almeida (Unicamp). O texto recebeu colaboração de Juliana Fracaro da Silva, graduanda no curso de Serviço Social da Unifesp

3 Femenagem é o termo utilizado no movimento feminista para demonstrar o reconhecimento a um ato ou trabalho desenvolvido por uma mulher. 
bua com a construção de uma educação antirracista e promotora da justiça social, cultural e econômica no cotidiano da vida social.

Nossa tarefa nesse processo é demarcar a defesa de um projeto popular de educação em direitos humanos que: assegure a concepção de homem/ mulher como sujeitos históricos, problematize a história das lutas sociais, afirme valores e princípios humanizadores - democracia de base, participação ativa, liberdade, dignidade e respeito à diferença como parte da vida social - e aponte, sobretudo, para a necessidade histórica da construção de um projeto de sociedade sem exploração e sem opressão.

Este artigo está estruturado em três partes. Na primeira, será problematizada a relação do 'Estado', 'democracia' e 'educação em direitos humanos', para visibilizar as disputas na contemporaneidade do projeto de educação em direitos humanos e a fragilidade das instituições democráticas no Brasil. Na segunda parte, a 'educação popular' como práxis da educação em direitos humanos, na disputa com a concepção da educação bancaria, mercantil, domesticadora das classes subalternas. E, por fim, serão apresentados os desafios da democracia e educação em direitos humanos na contraditória sociedade capitalista, e a exigência das lutas sociais para novos enfrentamentos, que contribuam com a educação em direitos humanos como projeto de educação emancipadora.

\section{Estado, democracia e educação em direitos humanos}

A disputa na contemporaneidade do projeto de educação em direitos humanos exige a centralidade da democracia, de modo que se consiga trazer para o horizonte da sociedade o sentido coletivo do acesso ao patrimônio público, por meio das políticas públicas. Universalizar direitos na sociedade capitalista é atuar nas brechas políticas do movimento contraditório da sociedade e do Estado, considerando que a estrutura e dinâmica do sistema se colocam para o conjunto das relações sociais como algo impensável de ser modificado.

Por isso, Marilena Chauí, ao refletir o conceito de democracia, convoca-nos a pensarmos para além da ideia de um regime político identificado à forma de governo, tendo em vista que "uma sociedade é democrática quando institui algo mais profundo, que é condição do próprio regime político, ou seja, quando institui direitos." (2005, p. 24).

Quando a sociedade é fundada com base nos direitos da população, a democracia está apta a diferenciá-los de privilégios e carências. Um privilégio é, por definição, algo particular, que não pode generalizar-se e nem universaliza-se. Uma carência é uma falta também particular ou específica que desemboca numa demanda também particular. Já um direito é algo geral e uni- 
versal, seja porque é válido para todos os indivíduos, grupos e classes sociais; seja porque, embora diferenciado, é reconhecido por todos (CHAUI, 2005).

Desde a promulgação da Constituição Federal, em 1988, foram criados vários canais de participação popular. Entretanto, o processo de participação exige aprendizado. A recente democracia brasileira ainda não está consolida da, por isso, a distância entre a lei e a realidade.

O Estado brasileiro, ainda não implementou com densidade os espaços de participação popular; e quanto o fez, criou um conjunto de procedimentos que dificulta a permanência dessa participação. Um exemplo são os colegiados escolares e associação de pais e docentes existentes na política educacional, cujo investimento na participação popular, é residual. As experiências de gestão democrática nas redes de educação existentes demonstram o quanto os investimentos contribuem com a mudança na cultura política participativa das crianças, adolescentes, jovens, adultos e idosos, que impulsionam relações participativas, horizontais e colaborativas, tanto na escola, como na família e comunidade local.

Assim, o controle público, conteúdo político do controle democrático, representado pelas organizações da sociedade civil - arrefeceu a disputa dos espaços políticos, considerando que as correlações de forças tiveram baixa densidade para a luta contra hegemônica por projetos societários. Refletir, debater e formular políticas públicas têm a ver com o cotidiano e com a realidade social. Os processos participativos são essenciais na elaboração das políticas públicas, por isso que a maior parte dos órgãos públicos participativos é paritária; essa conquista faz parte do patrimônio político brasileiro.

A forma filosófica com que Paulo Freire escreveu o livro Pedagogia da Autonomia (2003) convida-nos a refletir sobre vários saberes essenciais à prática educativa. Um deles é a necessária relação entre a ética e a estética.

Mulheres e homens, seres históricos-sociais, nos tornamos capazes de comparar, de valorar, de intervir, de escolher, de decidir, de romper, nos fizemos éticos... Estar sendo é a condição, entre nós, para ser. Não é possível pensar os seres humanos longe ou pior, fora da ética, quanto mais fora dela... É por isso que transformar a experiência educativa em puro treinamento técnico é amesquinhar o que há de fundamentalmente humano no exercício educativo: o seu caráter formador (2003, p. 33).

Paulo Freire nos convoca ao duplo movimento da ação e reflexão e traz para a centralidade a função do processo educativo, o qual mobiliza a reflexão densa da realidade e a tomada de decisões, para a convivência humana.

No mesmo sentido, Gramsci (1999) reflete nos Cadernos do Cárcere, que, para a realidade social, é mais importante uma multidão de pessoas ser conduzida a pensar coerentemente e de maneira unitária a realidade presen- 
te como um fato "filosófico" e "original" do que a descoberta, por parte de um "gênio" filosófico, de uma nova verdade que permaneça como patrimônio de pequenos grupos intelectuais (p. 95). Essa concepção de que o aprendizado teórico-político-filosófico é parte de um projeto de educação em disputa e, para além do capital, está no devir histórico, quando considera tanto a concepção da filosofia quanto da história, sendo esses elementos constitutivos do movimento dialético da realidade.

Essas análises nos apontam para a luta coletiva, a fim de construirmos processos que incidam no desmonte da emenda constitucional 95/2016 ${ }^{4}$, quando vivemos mais um golpe em relação às perdas dos direitos sociais coletivos.

É sabido que na sociabilidade capitalista é impossível a socialização da riqueza, mas precisamos lutar pela redução das desigualdades e defender a democracia, elemento central na luta por equidade e igualdade social.

Partimos do entendimento de que os direitos humanos, conforme Pini e Adriano (2011), "não apresentam forma e abordagem conceituais unívocas, mas respondem aos interesses de forças e classes sociais, em determinadas conjunturas e momentos históricos" (p.15-16). Nessa correlação de forças é que forjamos lutas em prol da educação em direitos humanos, que se torna incompatível com o sistema capitalista, o qual se alimenta da desigualdade, exploração e opressão. Entretanto, são nas brechas desse sistema que disputamos a agenda dos direitos sociais, políticos e econômicos, para alcançarmos a emancipação política, tendo como horizonte a emancipação humana.

\section{Educação popular como práxis da educação em direitos humanos}

Antes de abordarmos a educação popular como práxis da educação em direitos humanos, temos que explicitar o significado e a complexidade da educação na sociedade contemporânea que a mercantiliza transformando-a em um instrumento de domesticação e apassivamento das classes subalternas.

Em uma análise sobre a história da educação desde a comunidade primitiva até chegarmos ao mundo contemporâneo, Aníbal Ponce (1986) nos revela a questão chave da educação, que é a divisão da sociedade em classes sociais e o dualismo educacional que suscitou dessa divisão. Sendo assim, a educação se torna desigual com e pela divisão da sociedade em classes, tendo o seu agravamento na sociedade capitalista.

4 A emenda aprovada no Congresso Nacional alterou o regime fiscal que regula o ciclo orçamentário e ordena o congelamento por 20 anos de novos investimentos públicos, o que significa que uma geração nascerá sem ter no horizonte o acesso às políticas sociais básicas, caso a emenda não seja revogada. 
Na sociedade dividida em classes antagônicas - dominantes e dominados, servos e senhores, escravizados e latifundiários e, posteriormente na sociedade capitalista, empresários bilionários e classe trabalhadora -, a educação se torna uma "propriedade praticamente exclusiva das classes dominantes" (PONCE, 1986, p. 10), tendo as classes dominadas conquistado, ao longo dos séculos e com muita luta, o acesso irrestrito à educação, ou seja, a educação como um direito.

No decorrer dos séculos da história da educação, mesmo que as classes subalternas tenham conquistado a educação como um direito, a educação destinada a elas tinha como objetivo a manutenção do status quo da classe dominante, isto é, era encarregada de difundir e reforçar seus privilégios. Logo, a educação reservada às classes subalternas não incorporava os diferentes sujeitos sociais, como seres pensantes, como seres de necessidades e como seres responsáveis pela sua vida e pela transformação da mesma e da sociedade. Sua educação foi determinada única e exclusivamente para o fazer laboral; em outras palavras, para o trabalho em prol do enriquecimento da classe dominante.

No Brasil, um país dependente e periférico, a situação não foi diferente. Tivemos uma educação violenta e colonizadora desde que o país foi invadido pelos portugueses e, ao passar dos séculos, só conseguimos conquistar a educação como direito com muita articulação/mobilização e luta. Ainda assim, nos foi negada uma educação verdadeiramente integral. Há e sempre houve uma disputa do projeto educacional brasileiro e, mesmo com a consolidação da educação como direito, ela chega fragmentada para a classe trabalhadora, de forma a reproduzir a ideologia no sistema vigente, pois não abarca e compreende a vida, a cultura, e a transformação dessas classes, e sim, destina-se ao trabalho, à domesticação, à obediência e à submissão.

Para Gadotti (2016):

Tivemos muitas conquistas nessas últimas décadas, mas, no campo da educação, não conseguimos construir uma cultura democrática, cidadã, de solidariedade, de companheirismo e de compromisso com a transformação social. Entendemos que houve um sério descuido com a formação política e isso abriu espaço para o que estamos presenciando nesses anos mais recentes: a manipulação que incute a intolerância e o ódio (p.151).

O autor nos convoca a refletir sobre o quanto a nossa educação vive sitiada pela classe dominante, e nas conjunturas políticas mais favoráveis para os avanços democráticos; o quanto é preciso avançar na politicidade do processo de ensino e aprendizagem, de modo a resistir ao projeto de manipulação e não ficarmos refém de ideologias propagadas pelo capital como forma de reproduzir os seus ideais, exemplo disso é o "Projeto Escola Sem Partido". 
Desde 2015, esse projeto começou a tramitar tanto no Congresso Nacional, como nos estados e municípios. "O objetivo desse movimento é silenciar vozes, criminalizando o trabalho docente; é perseguir, demitir e até prender docentes que defendem uma visão de mundo contrária ao status quo e colocar a educação a serviços dos interesses do mercado" (GADOTTI,2016, p153).

Para contrapor aos retrocessos no campo da educação será preciso o fortalecimento da práxis educação popular, pois ela nasce justamente opondo-se a essa educação alienadora, denominada por Paulo Freire (1987), como educação bancária. Sendo assim, a educação popular surge como uma alternativa para a classe trabalhadora construir outra forma de educação, outra perspectiva de relações sociais, da qual a educação popular é o fio condutor de um projeto popular de educação.

Afirma Brandão (2019) que não existe um marco histórico específico para o surgimento da educação popular. Seu conceito, e seu entendimento, foi sendo cunhado a partir dos anos de 1960 por movimentos sociais ligados ou não à educação, mas que tinham como determinantes a participação popular e a cultura popular. Mesmo não havendo um marco histórico, pode-se afirmar que a educação popular foi construída a partir da experiência do Projeto de Alfabetização de Jovens e Adultos, coordenado pelo educador Paulo Freire, sendo emblemática a experiência ocorrida em Angicos (RN), em 1963. O projeto se destacou por sua metodologia e por ser uma proposta inovadora e libertadora, pois, a partir da Leitura do Mundo e do Círculo de Cultura trazia uma

[...] noção de aprender a partir do conhecimento do sujeito, a noção de ensinar a partir de palavras e temas geradores, a educação como ato de conhecimento e de transformação social e a politicidade da educação são apenas alguns dos legados da Educação Popular à pedagogia crítica universal [...] (GADOTTI, 2000, p. 6).

A experiência de Angicos teria se efetivado em política de educação para a eliminação do analfabetismo na gestão do presidente João Goulart, se a ditadura cívico-empresarial militar (1964-1985) não tivesse se instalado no Brasil.

Posto isso, o projeto de educação aspirado por Paulo Freire tem convictamente a educação como um ato político e emancipador, que permite a transição da sua consciência ingênua para a consciência crítica:

[...] uma educação que tentasse a passagem da transitividade ingênua à transitividade crítica, somente como poderíamos, ampliando e alargando a capacidade de captar os desafios do tempo, colocar o homem brasileiro em condições de resistir aos poderes da emocionalidade da própria transição. Armá-lo contra a força dos irracionalismos de que era presa fácil, na emersão que fazia, em posição transitivamente ingênua [...] (FREIRE, 2008, p.94)

Assim, esse modelo de educação provocaria uma consciência/curio- 
sidade crítica, tendo em vista que permitiria aos trabalhadores e trabalhadoras se reconhecerem como fazedores de cultura, protagonistas do mundo e transformadores da sociedade, com o objetivo de alcançar essa consciência crítica e responsabilidade cidadã que permitissem enxergar quem os oprimia e ceifava a sua vida. Nas palavras de Freire (2008)

Uma educação que possibilitasse ao homem a discussão corajosa de sua problemática. De sua inserção nesta problemática. Que o advertisse dos perigos de seu tempo, para que, consciente deles, ganhasse a força e a coragem de lutar, ao invés de ser levado e arrastado à perdição de seu próprio "eu", submetido às prescrições alheias. Educaçã̃o que o colocasse em diálogo constante com o outro. Que o predispusesse a constantes revisões. A análise crítica de seus "achados". A uma certa rebeldia, no sentido mais humano da expressão. Que o identificasse com métodos e processos científicos. $(p, 97)$

Desse modo, temos que entender a educação como um processo de transformação das pessoas e de pensamento, no caso da educação popular tem-se a compreensão de que todas(os) carregam saberes de suas vivências. Porém, não temos todo o conhecimento do mundo, ou seja, fazemos e reproduzimos cultura, mas também somos seres inacabados e estamos sempre aprendendo, se reinventando e se transformando. Esse modo de apreender a educação ocorreria de forma mútua, por meio do compartilhamento de saberes e múltiplas culturas e, por meio dessa socialização de saberes chegaríamos coletivamente ao fortalecimento da dimensão social, uma das condições para a transformação da sociedade.

Por isso que a consciência crítica amplia processos democráticos, Como afirma Paulo Freire:

Quanto mais crítico um grupo humano, tanto mais democrático e permeável, em regra. Tanto mais democrático, quanto mais ligado às condições de sua circunstância. Tanto menos experiências democráticas que exigem dele o conhecimento crítico de sua realidade, pela participação nela, pela sua intimidade com ela, quanto mais superposto a essa realidade e inclinado a formas ingênuas de encará-la. As formas ingênuas de percebê-la. A formas verbosas de representa-la. Quanto menos criticidade em nós, tanto mais ingenuamente tratamos os problemas e discutimos superficialmente os assuntos. (FREIRE, 2008, p. 103).

Sendo assim, a educação passaria a ser um projeto de emancipação popular voltada à ampliação da consciência crítica dos sujeitos sobre a sua realidade e da sua condição de classe oprimida em busca de libertação.

Como evidencia Bell Hooks, em seu livro Ensinando a Transgredir (2017), a educação só terá sentido e proporcionará o descobrir e o despertar da consciência das mulheres e dos homens, se ela estiver ligada ao seu modo de viver 
e aos seus saberes já acumulados. A educação não pode ser apenas um mero instrumento de transferência de informações que não fazem sentido para a vida cotidiana dos sujeitos, e que não proporcionam a superação de seus problemas.

Mesmo que não tenha sido implementada como política pública de educação (e ainda lutamos por isso), a educação popular, por meio de seus fundamentos teórico-metodológicos foi incorporada de várias formas e em muitos processos de ensino e aprendizagem pelo país e pelo mundo ${ }^{5}$. A exemplo, destacam-se as escolas do Movimento Sem Terra (MST), que densamente estruturou em todos os níveis de ensino a pedagogia da educação popular, permitindo às crianças, adolescentes, jovens, adultos e idosos uma educação emancipadora, que possibilita um aprendizado de cunho político e com qualidade social, política e ética, conseguindo, mesmo com as imposições da Base Comum Curricular (2017), construir, coletivamente com a comunidade do movimento, uma matriz curricular que garantisse uma educação emancipadora.

A educação popular foi e é incorporada e reinventada pelos movimentos sociais, escolas, educadores(as), cursinhos populares, projetos de extensão universitária e demais coletivos que compreendem a necessidade e a importância da alteração da configuração da educação que temos hoje, assim como a superação dessa sociedade capitalista que utiliza-se da educação como instrumento de dominação alienante.

O golpe contra a democracia, protagonizado pelo sistema político, em 2016, fragilizou o Estado brasileiro e a organização político-organizativa das lutas sociais. Consequentemente, colocou a população mais distante da socialização da política, impossibilitando a participação político-popular de modo mais estruturante.

Nossa luta, que já vem de muitos anos, intensifica-se nesse momento em que a ideia de educação como mercadoria foi instalada e assumida desde o golpe cívico-militar-empresarial de 1964, mas que se intensifica com a edificação do projeto neoliberal iniciado nos anos 1990, e culminou com "o golpe de 2016", o qual só é possível de ser compreendido por meio das análises dos múltiplos processos políticos desencadeados nos governos de Lula e Dilma.

A decisão das instâncias supremas do país - Congresso e STF - fez
Dilma Rousseff deixar a presidência em definitivo no dia 31 de agos-
to de 2016 . Seu respeito pelas instituições da democracia foi maior
que fragilidade do caráter daqueles que a destituíram. Se algum cri-
me fosse revelado na gravidade com que se polemizou, não haveria
necessidade de tanto teatro. Toda a engenharia social que desem-

5 Vale lembrar que Paulo Freire, formulador desta teoria educacional, é um dos autores mais citados no mundo em diversas áreas do conhecimento. 
bocou em 2016 foi fruto da pretensão de alguns, da articulação de outros, de erros do próprio governo, mas também de seus acertos. (GUERRA, 2017, p. 85

Após esse processo de 2016, a intensificação da educação como mercadoria de base conservadora, moralizante e manipuladora ganha espaço na agenda da política pública nacional e a práxis da educação popular vai resistir nos espaços dos movimentos sociais e nas instituições de ensino, que já tinham acúmulo nesse debate.

À vista disso, faz-se imprescindível adotarmos a educação popular como práxis da educação em direitos humanos, para lutarmos em sua defesa e para que ela seja concebida como política pública e acessível a todas e todos. Será, por meio dela, que conseguiremos desvelar coletivamente o que está obscuro e nos leva à servidão e à morte. A partir da capacidade e responsabilidade para alterar essa condição, conseguiremos lutar, transformar e conquistar os objetivos da educação em direitos humanos.

\section{Desafios da educação em direitos humanos}

Relacionar democracia e educação em direitos humanos nesta contraditória sociedade capitalista faz-se necessário para que possamos construir novos enfrentamentos, por meio das lutas sociais e afirmar educação em direitos humanos no debate crítico acerca das múltiplas questões que envolvem a educação, a mídia, o sistema de justiça e segurança pública e a sociedade em geral.

Desse modo, compreendemos a educação em direitos humanos como aquela que parte da história e tem a realidade como ponto de partida para construção e a difusão do conhecimento, por meio dos percursos educativos. Os valores da democracia, reconhecimento e convivência com as diferenças/diversidade, a pluralidade de pensamento e a participação efetiva nos processos da vida social compõem a práxis de todos/as envolvidos/as. (PINI; SILVA, 2020)

A educação em direitos humanos promove aprendizado político e coletivo das lutas sociais e impulsiona o fortalecimento do projeto de educação pública, popular, laica e socialmente referenciada em uma teoria social crítica.

Temos como desafio a disputa pelo fundo público, articuladamente com movimentos de base, sindicatos e partidos políticos, para que as condições objetivas de vida de todas as pessoas sejam garantidas social e economicamente por meio do Estado.

Para frear o Estado brasileiro na desconstrução da política de educação em direitos humanos faz-se necessário a reconstrução democrática com as lutas sociais de base e engajamento da população brasileira. 


\section{Referências}

ALMEIDA, Silvio. Racismo estrutural. Belo Horizonte: Letramento, 2018.

BRANDÃO. Carlos Rodrigues. Quando a educação tornou-se educação popular. São Paulo, 2019.

BRASIL. [Constituição (1988)]. Constituição da República Federativa do Brasil. Brasília, DF: Senado, 1988.

CHAUI, Marilena. Considerações sobre a democracia e os obstáculos à sua concretização. In: TEIXEIRA, Ana Cláudia Chaves (org.). Os sentidos da democracia e da participação. São Paulo: Instituto Pólis, 2005.

FREIRE, Paulo. Pedagogia da autonomia. Saberes necessários à prática educativa. Rio de janeiro: Paz e Terra, 27. ed., 2003.

FREIRE, Paulo. Pedagogia do oprimido. São Paulo: Rio de Janeiro: Paz e Terra, 17. ed., 1987.

FREIRE, Paulo. Educação como prática da liberdade. Rio de Janeiro: Paz e Terra, 31. ed., 2008.

GADOTTI, Moacir. Perspectivas atuais da educação. Revista São Paulo em Perspectiva, São Paulo, v. 14, n. 2, p. 3-11, 2000.

GADOTTI, Moacir. A escola cidadã frente ao "Escola Sem Partido". In: Ação Educativa, Assessoria, Pesquisa e Informação (org.). A ideologia do movimento Escola Sem Partido: 20 autores desmontam o discurso. São Paulo: Ação Educativa, 2016. p. 149-160. Disponível em: https://acaoeducativa.org.br/wpcontent/uploads/2017/05/escolasempartido_miolo.pdf. Acesso em 24 nov. 2021.

GRAMSCI. Antonio. Caderno do Cárcere. [Introdução ao estudo da filosofia. A filosofia de Benedetto Croce.] v. 1. Tradução Carlos Nelson Coutinho. Rio de Janeiro: Civilização Brasileira, 1999.

GUERRA, Alexandre et al. Brasil 2016: recessão e golpe. São Paulo: Fundação Perseu Abramo, 2017. Disponível em: https://marxismo21.org/wp-content/ uploads/2012/12/Alexandre-Guerra-et-al.-Brasil-2016.-Recess\%C3\%A3o-e- 
golpe-2017.pdf. Acesso em: 19 nov. 2021

HOOKS, BELL. Ensinando a transgredir. São Paulo: Editora WMF Martins Fontes, 2017.

PINI, F. R. O.; SILVA, M. L. O. Educação em direitos humanos, participação e o Estatuto da Criança e do Adolescente. In: FÁVERO, E. T.; PINI, F. R. O.; SILVA, M. L. O. (org.). ECA e a Proteção Integral de Crianças e Adolescentes. São Paulo: Cortez, 2020. p.163-180.

PINI, Francisca Rodrigues de Oliveira e MORAES, Célio Vanderlei (org.). Educação, participação política e direitos humanos. São Paulo: Editora Instituto Paulo Freire, 2011.

PONCE, Aníbal. Educação e luta de classes. São Paulo: Cortez, 1986. 